\title{
Electrocatalytic Oxidation of Sulfur Dioxide by Iron Phthalocyanine Monolayer in Aqueous Solutions
}

\author{
Sunghyun Kim \\ Department of Chemistry and Bio Molecular Informatics Center, Konkuk Lmiversin, Seoul 143-701. Korea \\ Received Julv 11,2002
}

Key Words : $\mathrm{SO}_{2}$ oxidation. Iron phthalocyanine. Passivation. Electrocatalysis

The SO_ oxidation has been paid much attention due to its technological applications in the field of energy production. ' flue gas desulfurization. " and electrowinuing of sulfide ores. ${ }^{3}$ Most work so far has been done using pure metal particularly platinum and gold electrodes ${ }^{4-6}$ in aqueous solutions. The reactions on these surfaces are highly complicated depending on many factors such as surface pre-treatment. potential range excursed. and the presence of oxides films and thus there is not quite an agreement about the kinetics and mechanisms. Seo and Sawyer ${ }^{5}$ suggested that the oxidation of $\mathrm{SO}_{2}$ proceeds in two steps: one a pure electron transfer process and the other a chemical oxidation by electrolytically formed metal oxides. Lal and coworkers ${ }^{7 \delta}$ reported that $\mathrm{SO}_{2}$ is reduced via an SO intermediate which can be singly- or doubly-bonded to the surface. From studies in concentrated sulfuric acid. Apply by and Pichon suggested $\mathrm{SO}_{2}$ is oxidized to sulfuric acid via the formation of dithionate as a rate-determining step. Recent studies appear to suggest the formation of dithionate ion in weakly acidic to weakly basic solutions. Katagiri and Matsubara suggested ${ }^{9}$ that $\mathrm{Cu}(\mathrm{II})$ ion catalyzes $\mathrm{SO}_{3}{ }^{-2}$ oxidation to $\mathrm{S}_{3} \mathrm{O}_{6}{ }^{2-}$ via the formation of binuclear $\mathrm{Cu}(\mathrm{II})$ complex by Raman spectroscopy. From radiotracer study. Vargar et $a l^{10}$ suggested the oxidation of $\mathrm{SO}_{2}$ to $\mathrm{S}_{2} \mathrm{O}_{6}{ }^{-}$- on a gold electrode

While most researches to date have been carried out on metal surfaces the electrocatalytic oxidation of $\mathrm{SO}_{2}$ by adsorbed macrocycles has not been studied to our knowledge. There is only a report on the electrochemical transformation of sulfur oxoanions using water-soluble iron porphỵrins. ${ }^{11}$

We have been working on electrocatalytic reactions of $\mathrm{NO}_{\mathrm{K}}$ and $\mathrm{SO}_{\mathrm{x}}$ using metallo-phthalocyanines. Among them. iron phthalocyanine $(\mathrm{FePc})$ was proven to be particularly effective for $\mathrm{NO}$ and $\mathrm{SO}_{2}$ reduction reactions ${ }^{3-14}$ when adsorbed on the surface. The electronic and structural changes upon the surface ${ }^{15.16}$ as well as in a sol-gel matrix ${ }^{17}$ have also been studied in our group. Based on these previous works. we have tried in this paper the oxidation of $\mathrm{SO}_{2}$ by the adsorbed $\mathrm{FePc}$ monolayer on the electrode surface in aqueous solutions as a function of $\mathrm{pH}$.

\footnotetext{
Corresponding author. Phone: +82-2-450-3378, Fax: +82-2-456-
} 2744, E-mail: skinn 100akonkuk.ac.ks

\section{Experimental Section}

All the chemicals were of analytical grade and used without further purification. The $\mathrm{SO}_{2}$ concentration was controlled by adding concentrated sodium sulfite solution $(1.0 \mathrm{M})$ to the electrolyte. $18 \mathrm{M}$ deionized water (Millipore $\mathrm{Co}$.) was used to prepare solutions. Adsorption of $\mathrm{FePc}$ (Aldrich) onto the edge plane of OPG (ordinary pyrolytic graphite. Union Carbide) was effected by dipping the electrode in a FePc-dissolved DMSO solution. The working electrode was made by molding an OPG piece into the Kel-F plastic and exposing the edge plane. In each experiment. the electrode was ground against 2000 -grit $\mathrm{SiC}$ paper to ensure the fresh surface.

Electrochemical measurements were performed with a typical three-electrode system and a potentiostat (Autolab PGSTAT 30. ECO CHEM). A Ag $|\mathrm{AgCl}| \mathrm{KCl}(3 \mathrm{M})$ reference and $\mathrm{Pt}$ counter electrodes were used. All the measurements were carried out in buffer solutions at room temperature. Buffer solutions in the range of $\mathrm{pH} 3$ to 9 were made using $\mathrm{KHP}$ adjusted by $\mathrm{H}_{2} \mathrm{SO}_{4}(\mathrm{pH} 3$ and 4$)$ and $\mathrm{NaOH}(\mathrm{pH} 5)$. $\mathrm{KH}_{2} \mathrm{PO}_{4}$ adjusted by $\mathrm{NaOH}(\mathrm{pH} 6$ and 7 ). and tri(hydroxymethỵl)anminomethane adjusted by $\mathrm{NaOH}(\mathrm{pH} 8$ and 9). For $\mathrm{pH} 1$ and 2 buffers. sulfuric acid was used and the ionic strength was adjusted by sodium sulfate.

\section{Results and Discussion}

Figure 1 shows a series of cyclic voltammograms of $\mathrm{SO}_{2}$ $(2 \mathrm{mM})$ oxidation by the $\mathrm{FePc}$ at different $\mathrm{pHs}$. The coverage of $9.1 \times 10^{-10} \mathrm{~mol} \mathrm{~cm}{ }^{-2}$ is much larger than that of tetrasulfonated $\mathrm{FePc}$ on the basal plane of HOPG (highly oriented pyrolytic graphite). This is due to the rough nature of the edge plane of OPG. Taking the interfacial capacitances of OPG (ca. $\left.280 \mu \mathrm{F} \cdot \mathrm{cm}^{-2}\right)$ and HOPG $\left(c a .3 \mu \mathrm{F} \cdot \mathrm{cm}^{-2}\right)^{1 \S}$ into consideration. $\mathrm{FePc}$ can be regarded as existing as a monolayer. $[\mathrm{Fe}(\mathrm{III}) \mathrm{Pc}(-2)]^{+}$, an oxidized form of $\mathrm{FePc}$. exhibits electrocatalytic activities whose peak potential remains constant up to $\mathrm{pH} c a$. 4 and shifts negatively by 60 $\mathrm{m} \mathrm{V}$ per $\mathrm{pH}$ (data not shown). Without a FePc layer. no $\mathrm{SO}_{2}$ oxidation takes place over a wide potential range. The $\mathrm{pH}-$ dependence of $\mathrm{SO}_{2}$ oxidation peak potential does not show a constant variation in accord with $\mathrm{FePc}$ redox peak. Most notable is that even with a cathodic scan. the oxidation current is observed in strongly acidic solutions. This is 


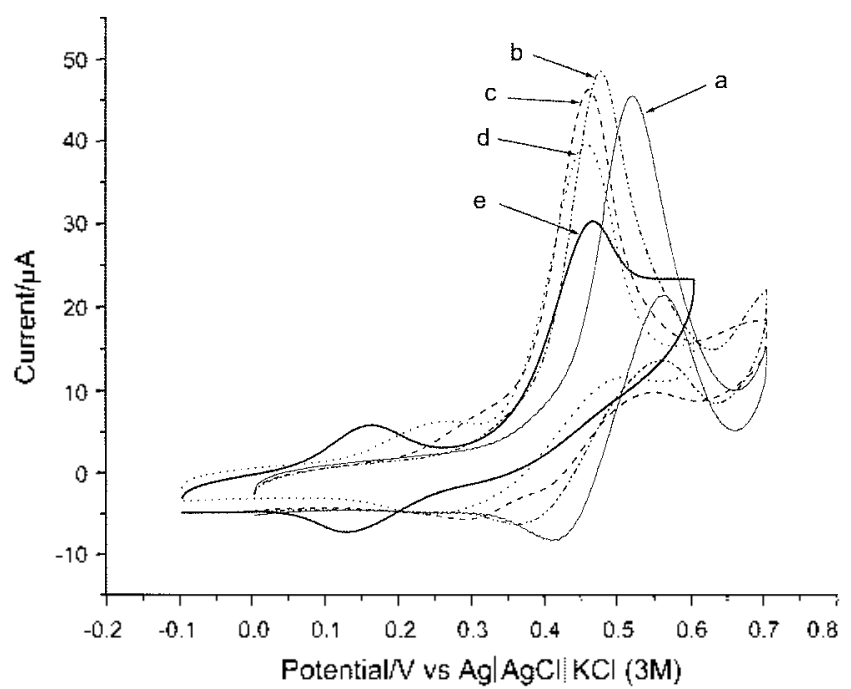

Figure 1. Cyclic voltammetry of $\mathrm{SO}_{2}$ oxidation by the FePcadsorbed electrode at $\mathrm{pH} I$ (a), 2 (b), 3 (c), 5 (d), and 7 (e). $\mathrm{C}_{\mathrm{SO}_{2}}=$ $2.0 \mathrm{mM}$, scan rate $=0.2 \mathrm{~V} \cdot \mathrm{s}^{-1}$. Apparent electrode area $=0.04 \mathrm{~cm}^{2}$.

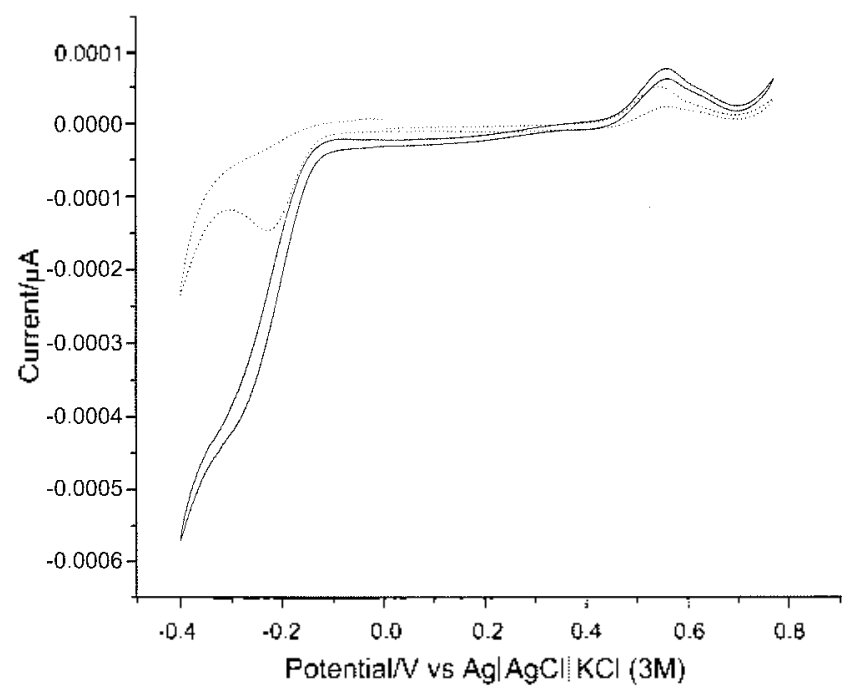

Figure 2. Rotating disk electrode experiments for the $\mathrm{SO}_{2}$ oxidation and reduction at $\mathrm{pH} 1$ with (solid, $1000 \mathrm{rpm}$ ) and without (dotted) rotation. $\mathrm{C}_{\mathrm{SO}_{2}}=2.0 \mathrm{mM}$, scan rate $=0.1 \mathrm{~V} \cdot \mathrm{s}^{-1}$. Apparent electrode area $=0.1 \mathrm{~cm}^{2}$

characteristic of passivation. implying that the surface is inactivated by the adsorption of an oxidized product of $\mathrm{SO}_{2}$. As the potential is scanned positively: more and more $\mathrm{SO}_{2}$ molecules are oxidized and the number of active sites becomes smaller. resulting in the decrease in oxidation current. On the reverse scan. the active site begins to reappear and the oxidation takes place as a result. The fact that the current drop is due to the passivation was confirmed by the experiment with a rotating disk electrode (Figure 2). While a typical sigmoidal shape due to the constant mass transport of $\mathrm{SO}_{2}$ to the electrode was observed for the reduction. the same current pattern of V-shape was resulted for the oxidation. However, the effect of scanning to the $\mathrm{SO}_{2}$ reduction region was to decrease the oxidation current due to the formation of sulfur layer over the FePc monolayer. This
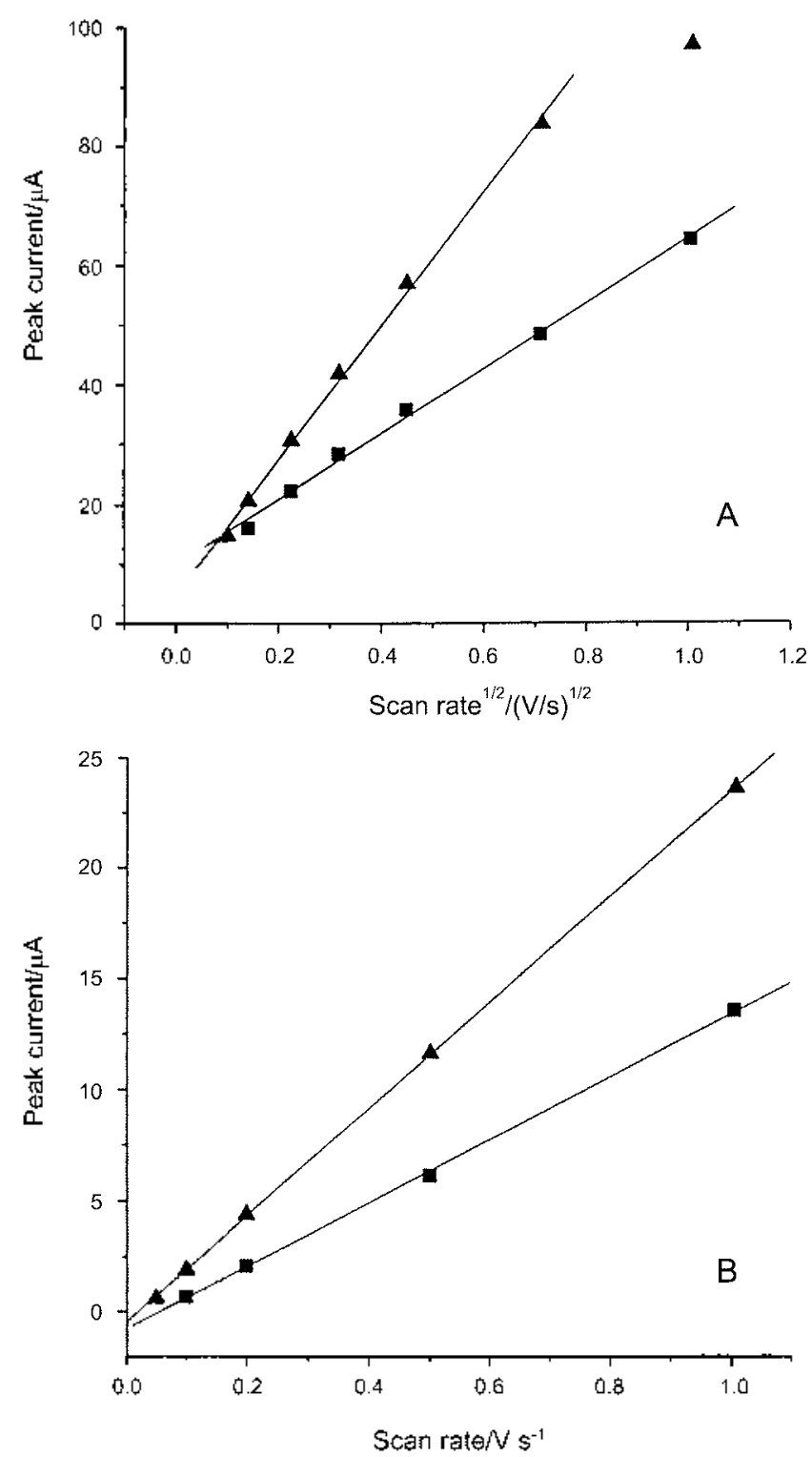

Figure 3. Peak current dependence for $\mathrm{FePc}$-catalyzed $\mathrm{SO}_{2}$ oxidation on the scan rate. Panel A shows the plot of $i_{p} v s v^{1: 2}$ for the peak II at $\mathrm{pH} \mathrm{l}(\boldsymbol{\Delta})$ and $5(\boldsymbol{Q})$ and Panel B the plot of $i_{p}$ vs $v$ for the peak $\mathrm{I}$ at $\mathrm{pH} 5(\boldsymbol{\square})$ and 7 ( $\Delta$ ). $\mathrm{C}_{\mathrm{SO}_{1}}=2.0 \mathrm{mM}$. Apparent electrode area $=0.04 \mathrm{~cm}^{2}$.

sulfur layer is formed by disproportionation of sulfoxylic acid $\left(2 \mathrm{H}_{2} \mathrm{SO}_{2} \rightarrow \mathrm{S}+\mathrm{SO}_{2}+2 \mathrm{H}_{2} \mathrm{O}\right)$. which is produced by the $\mathrm{SO}_{2}$ reduction. This is contrary to the $\mathrm{Pt}$ case at which adsorbed sulfur promotes the $\mathrm{SO}_{2}$ oxidation. ${ }^{19}$ The $i_{p} v_{s} v^{1: 2}$ plot. where $i_{p}$ and $v$ are peak current and scan rate. respectively. produces a straight line. indicating that the oxidation process is diffusion-controlled regardless of $\mathrm{pH}$ (Panel $\mathrm{A}$. Figure 3). The passivation effect becomes weakened as the solution $\mathrm{pH}$ increases and thus $\mathrm{SO}_{2}$ is simply irreversibly oxidized to sulfate as a final product. The peak current slightly decreases with a $\mathrm{pH}$ increase and the oxidation is still observable even at alkaline medium. This is in sharp contrast to the case of $\mathrm{SO}_{2}$ reduction in that the sulfite ion is not reduced. ${ }^{l+}$ Three forms of sulfur species. $\mathrm{SO}_{2} . \mathrm{HSO}_{3}^{-}$. and $\mathrm{SO}_{3}{ }^{2-}$, are all electrochenically oxidizable. One of 


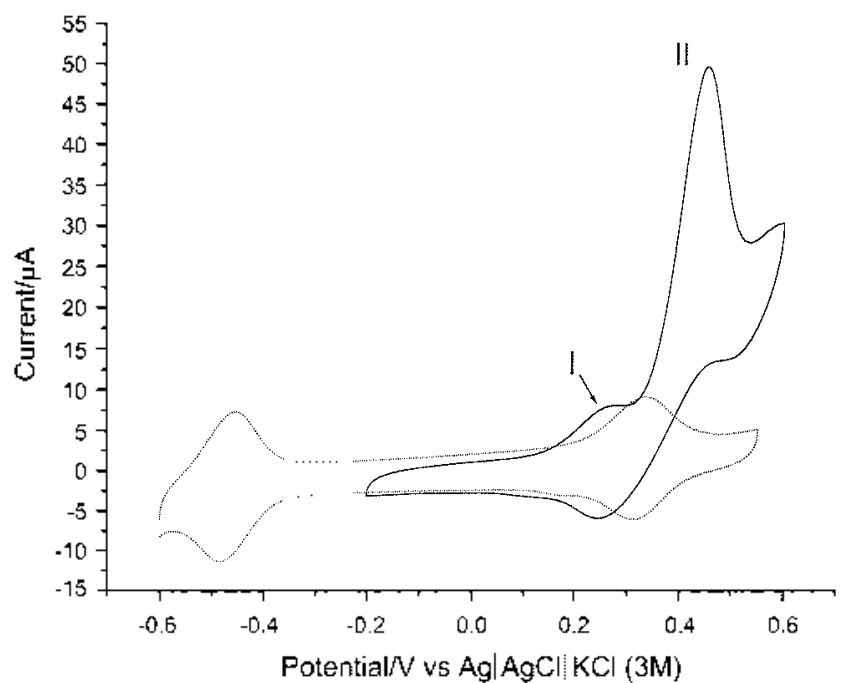

Figure 4. Cyclic voltammetry of the FePc-adsorbed electrode with (solid line) and without (dotted line) $\mathrm{SO}_{2}$ in a pH 5 solution. $\mathrm{C}_{\mathrm{SO}_{3}}=$ $2.0 \mathrm{~mm}$, scan rate $=0.2 \mathrm{~V} \cdot \mathrm{s}^{-1}$. Apparent electrode area $=0.04 \mathrm{~cm}^{2}$.

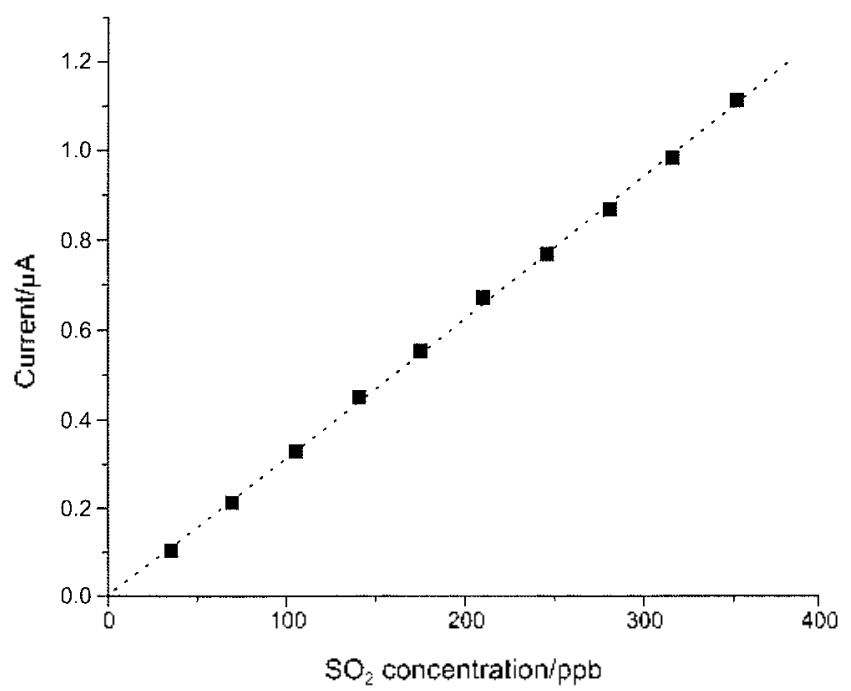

Figure 5. Plot of oxidation current vs $\mathrm{SO}_{2}$ concentration from amperometric experiments in $0.5 \mathrm{M}$ sulfuric acid. The electrode was rotated at $1000 \mathrm{ppm}$. The potential was held where the maximum oxidation current flows. Apparent electrode area $=0.1$ $\mathrm{cm}^{2}$. R-factor of fit $=0.9996$.

reasons for the current decrease could be explained by the decrease in diffusion coefficient for the charged species that can be solvated by the water molecules. The fraction of charged species increases as $\mathrm{pH}$ increases.

Above $c a . \mathrm{pH} 3$. there begins to appear a small reversible redox pair (peak I. Figure 4) before the main $\mathrm{SO}_{2}$ oxidation (peak II. Figure 4) takes place. This small peak grows larger as $\mathrm{pH}$ increases and still exists even in alkaline solutions. This peak is not due to the oxidation of adsorbed FePc since it appears before $\mathrm{Fe}(\mathrm{II}) \mathrm{Pc}(-2)$ oxidation initiates and is not observable at a low scan rate. We attribute this peak to the oxidation of $\mathrm{SO}_{2}$ to dithionate $\left(\mathrm{S}_{2} \mathrm{O}_{6}{ }^{2-}\right)$. Dithionate is known to be very unstable in strongly acidic solutions but becomes stable when the solution is made less acidic. The peak current is directly proportional to the scan rate (Panel B, Figure 3). indicating that dithionate fonnation is not diffusioncontrolled but surface process.

The possibility of a FePc-modified electrode as a $\mathrm{SO}_{2}$ sensor has been demonstrated by the amperometric detection of $\mathrm{SO}_{2}$ (Figure 5). A concentrated sulfite solution was added stepwise to the $\mathrm{SO}_{2}$-free electrolyte and current was measured at a potential where the oxidation occurred while rotating the electrode. A linear response was obtained down to ppb range, demonstrating this type of sensor has enough sensitivity for the practical use.

Acknowledgment. Financial support from Korea Research Foundation (Grant No. KRF-2000-041-D00220) is gratefully acknowledged. The author thanks $\mathrm{Mr}$. H. J. Choi for the assistance during the experiments.

\section{References}

1. Spotnitz, R. M.; Loeffler, C. E; Langer. S. H. J. Appl. Electrochem. 1981.11 .403 .

2. Lee. J.: Langer. S. H. J. Electrochen. Soc. 1992. 139. 3499.

3. Gonzales. J.: Capel-Boute. C.: Devroly. C. Electrochim. Acta 1965. 10,513

4. Spotnitz, R. M. Colucci, J. A.: Langer. S. H. Electrochim. Acta 1983. 28,1053

5. Seo. E. T.: Sawyer. D. T. Electrochim. Acta 1965. 10.239.

6. Appleby. A. J.: Pichon. B. J. Electromal Chem. 1979. 95. 59.

7. Contractor. A. Q.: Lal. H. J. Electroanal. Chent. 1978. 93.99.

8. Jayaram. R.: Contractor. A. Q: Lal, H. J. Electroanal Chent. 1978. 87,225

9. Katagiri. A.: Matsubara. T. J. Electrochem. Soc. $1988,135,1709$.

10. Varga. K.: Baradlai. P.: Vertes. A. Electrochin Acta 1997. 42. 1143.

11. Chen. S.-M.: Chiu. S.-W. Electrochin. Acta 2000. +5.4399.

12. Choi. H. J; Kwag, G.: Kim, S. J. Electroanal Chem. 2001. 508. 105 .

13. Kim. S.; Kwag, G. Bull Kowan Chem. Soc, 2002, 23, 25.

14. Yu. C. S.: Choi. H.: Kiml. S. Chem Lett. 2002. 7. 648.

15. Ha. S. Y.: Park. T.: Ohta. T.: Kwag. G.: Kim. S. Electrochent Solid State Lett 1999. 2.465.

16. Ha. S. Y.: Kwag. G.; Kim. S. Bull Korem Chem. Soc. 2000.21. 588.

17. Ha. S. Y.; Kim. S. J. Electromal. Chem 1999, +68.131.

18. Kiml. S.: Scherson. D. A. Anal Chem. 1992. 64. 3091.

19. Quijada. C.: Rodes. A.: Vazquez. J. L.: Perez. J. M.: Aldaz. A. J. Electromal. Chem. 1995.398. 105. 